\title{
Impacto do tratamento restaurador atraumático na ansiedade odontológica de escolares
}

Taís S. Barbosa (PQ), Juana R. S. Huamani (PG), Karina G. Sousa (PG), Camila N. Freitas (PG), Tiago M. Chieregatto (EM), Helem G. Oliveira (EM), Mariana S. Sabino (EM)

\section{Resumo}

Escolares, de 6 a 8 anos $\left(\delta^{\lambda}=57,1 \%\right)$, apresentaram ausência de ansiedade odontológica (antes e após o tratamento restaurador atraumático - TRA), comportamento ansioso relaxado (em todas as etapas do TRA) e maior frequência cardíaca ( $F C$ ) antes do TRA.

Palavras Chave: Ansiedade ao Tratamento Odontológico, Criança, Tratamento Dentário Restaurador Atraumático

\section{Introdução}

O tratamento odontológico contém diversos estímulos que causam medo e problemas comportamentais em crianças. ${ }^{1} \mathrm{O}$ tratamento restaurador atraumático (TRA) é uma alternativa eficaz para crianças ansiosas ${ }^{2}$, consistindo de um método "atraumático" por preservar mais estrutura dentária além de ser mais confortável para o paciente. ${ }^{3}$ Estudos prévios avaliaram a ansiedade somente após o TRA, ${ }^{4}$ sem determinar a relação causal entre estes fatores. Este estudo objetivou avaliar a ansiedade odontológica, antes e após o TRA, em 42 escolares com cárie (grupo experimental, GE), comparados ao grupo controle ( $\mathrm{GC}, \mathrm{n}=46$ ).

\section{Resultados e Discussão}

A ausência de ansiedade (Modified Venham Picture Test - VPT- $m=0)^{5}$ foi mais frequente em ambos os grupos (GC=78,3\%; $\quad \mathrm{GE}_{\text {[antes }}$ ${ }_{\mathrm{TRA}]}=78,6 \%$ ) e momentos $\left(\mathrm{GE}_{\text {[depois }} \mathrm{TRA]}=81 \%\right.$ ) (Figura 1). O comportamento relaxado (Modified Venham Anxiety Scale - VAS- $m=0)^{5}$ foi o mais frequente nas etapas do TRA (Figura 2). No GE, a frequência cardíaca ( $F C$ ) foi maior antes do TRA $(92,88 \pm 9,48)$ e menor após o TRA $(87,64 \pm 9,79)$ (Tabela 1).

Figura 1. Classificação da ansiedade (VPT-m) para cada grupo/antes e após o TRA.

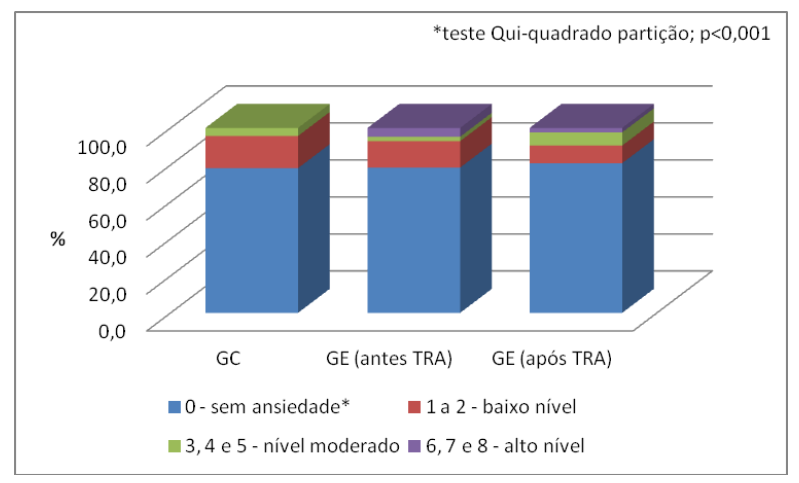

Figura 2. Classificação do comportamento ansioso (VAS-m) nas etapas do TRA (GE, $n=42$ ).

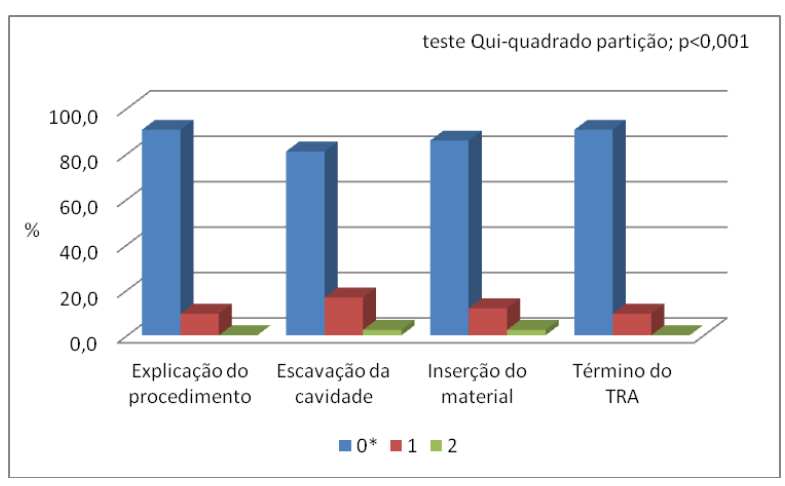

Tabela 1. Frequência cardíaca nas etapas do TRA (GE, $n=42$ ).

\begin{tabular}{lc}
\hline Etapas do TRA & Média $\pm \mathrm{DP}$ \\
\hline Antes & $92,88 \pm 9,48^{\mathrm{a}}$ \\
Explicação do procedimento & $89,40 \pm 10,50^{\mathrm{b}}$ \\
Escavação da cavidade & $88,24 \pm 11,33^{\mathrm{b}}$ \\
Inserção do material & $88,74 \pm 9,61^{\mathrm{b}}$ \\
Após & $87,64 \pm 9,79^{\mathrm{b}}$ \\
\hline
\end{tabular}

Letras diferentes significam diferença significativa entre os grupos (ANOVA dois critérios, pós-teste $t ; p<0,001$ )

\section{Conclusões}

O TRA não causou ansiedade nem a diminuiu no decorrer do tratamento de escolares.

\section{Agradecimentos}

À participação dos voluntários e ao apoio financeiro do PIBIC-EM e FAEPEX.

\footnotetext{
${ }^{1}$ ten Berge, M.; Veerkamp, J.S.; Hoogstraten, J. The etiology of childhood dental fear: the role of dental and conditioning experiences. J. Anxiety. Disord. 2002, 16, 321-9.

${ }^{2}$ Leal, S.C.; Abreu, D.M.; Frencken, J.E. Dental anxiety and pain related to ART. J. Appl. Oral. Sci. 2009, 17, 84-8.

${ }^{3}$ van Amerongen, W.E.; Rahimtoola, S. Is ART really atraumatic? Community. Dent. Oral. Epidemiol. 1999, 27, 431-5.

${ }^{4}$ Topaloglu-Ak, A.; Eden, E.; Frencken, J.E. Perceived dental anxiety among schoolchildren treated through three caries removal approaches. J. Appl. Oral. Sci. 2007, 15, 235-40.

5 Venham, L.; Bengston, D.; Cipes, M. Children's response to sequential dental visits. J. Dent. Res. 1977, 56, 454-9.
} 